\title{
LA REAL ACADEMIA DE BELLAS ARTES DE SAN CARLOS Y EL EJERCICIO DE LA AGRIMENSURA EN LA VALENCIA DEL SIGLO XVIII
}

\author{
Alfredo Faus Prieto
}

Doctor en Geografía

\section{RESUMEN}

En el siglo XVIII la agrimensura conoció, en España, un proceso inacabado de institucionalización que sentó las bases para su posterior desarrollo. Este proceso se inició en el antiguo Reino de Valencia y provocó la aparición sucesiva del empleo municipal y el título académico de agrimensor. En este trabajo se estudian las circunstancias que concurrieron en dicho proceso, así como sus limitaciones.

PALABRAS CLAVE: agrimensura, reino de Valencia (España), siglo XVIII, institucionalización.

\section{SUMMARY}

During the $18^{\text {th }}$ century the land surveying knew in Spain an unfinished process of institutionalizacion that laid the foundations of its further development. This process, which began in the ancient Reign of Valencia, provoked the successive aparition of local employment and the academic title of land-surveyor. The present work is focused on the circumstances wich took place in this process, as well as its limitations.

KEY WORDS: land surveying, reign of Valencia (Spain), $18^{\text {th }}$ century, institutionalization.

\section{INTRODUCCIÓN}

En la España del siglo XVIII diversos colectivos asistieron a la lenta institucionalización de su profesión. De estos grupos los que han merecido una mayor atención por parte de los investigadores han sido los formados por los maestros de obra-arquitectos ${ }^{1}$ y los

1 BASSEGODA, J. (1972), Los maestros de obras de Barcelona, Barcelona; BÉRCHEZ, J. (1987), Arquitectura y academicismo en el siglo XVIII valenciano, Valencia; Laborda, J. (1989), Maestros de obra $y$ arquitectos del período ilustrado en Zaragoza, Zaragoza. 
ingenieros militares ${ }^{2}$, mientras que en el caso que nos ocupa, el de los expertos en agricultura-agrimensores, este acercamiento ha sido más reciente ${ }^{3}$. Esto último resulta difícil de entender teniendo en cuenta la importancia y la diversidad de los trabajos realizados por estos profesionales. Por las manos de expertos y agrimensores pasaban cometidos como la medición, tasación, división y nivelación de terrenos, la delimitación de propiedades y términos municipales, el aforo de líquidos o la dirección de excavaciones y desmontes. Todos ellos, además, con el levantamiento, cada vez más necesario, de mapas y planos de situación. Podemos imaginarnos la repercusión que estas actuaciones tuvieron en empresas tan ambiciosas como la implantación del Catastro de Ensenada, la construcción de caminos reales o la apertura de canales y acequias, así como en los centenares de pleitos suscitados entre municipios y/o particulares.

En el antiguo Reino de Valencia, esta importancia se acrecentó en el siglo XVIII como consecuencia de un aumento demográfico que provocó la extensión del regadío e innumerables litigios por cuestiones terrioriales. Encargos como el mantenimiento de una red de acequias de origen medieval, su extensión a zonas de secano, el empadronamiento de las parcelas beneficiadas por el riego, el deslinde de zonas como la Albufera o las riberas de los ríos, de contornos cambiantes y administradores mal definidos, la delimitación de propiedades ante la continua usurpación de sus márgenes, su justiprecio en operaciones de compra-venta o divisiones por herencia o el control de los asentamientos ilegales, provocaron el aumento del número de expertos en agricultura y agrimensores y, al tiempo, la exigencia de una mayor dedicación y preparación por parte de los mismos. El resultado de todo ello fue el inicio de un proceso de institucionalización del oficio que tuvo su centro en la ciudad de Valencia.

\section{EL OFICIO DE AGRIMENSOR EN VALENCIA HASTA 1768}

A comienzos del siglo XVIII no existía en España ninguna institución que centralizase la expedición del título de agrimensor y/o controlase la preparación de las personas que se empleaban en este oficio. Hasta la segunda mitad del mismo, tales títulos (en realidad unas simples certificaciones) les eran concedidos a los interesados

2 CAPEL, H. et al. (1983), Los ingenieros militares en España. Siglo XVIII. Repertorio biográfico e inventario de su labor científica y espacial, Barcelona; y Capel, H. et al. (1988), De Palas a Minerva. La formación científica y la estructura institucional de los ingenieros militares en el siglo XVIII, Barcelona-Madrid.

3 FAUS, A. (1994), «El proceso de institucionalización de la agrimensura en la Valencia del siglo XVIII», Cuadernos de Geografía, 56, pp. 233-262; FAUS, A. (1995a), Mapistes. Cartografia i agrimensura a la València del segle XVIII, Valencia; y FAUS, A. (1995b), «El ejercicio profesional de la agrimensura en la España del siglo XVIII. Titulación académica y formación teórica de los peritos agrimensores», Llull, 35, pp. 425-440. Hasta la realización de la tesis doctoral que dio lugar a estas publicaciones la única referencia al colectivo de agrimensores estaba contenida en CAPEL, H. (1982), Geografía y Matemáticas en la España del siglo XVIII, Barcelona, pp. 304-314. No conocemos ningún estudio referido a la situación de la agrimensura en otras zonas de España. 
por los municipios y los tribunales en los que habían prestado sus servicios. Esta situación era muy distinta de la que existía en Francia o Italia, donde la formación de estos peritos interesaba directamente al estado. En el primer caso eran los ingenieros militares quienes impartían la docencia en las provincias de destino, mientras el gobierno central se encargaba de proporcionarles libros e instrumentos ${ }^{4}$. En el segundo, existían multitud de colegios profesionales desde el siglo XVI que no sólo expedían títulos, sino que se preocupaban de la capacitación técnica de los agrimensores. Así, los alumnos del de Milán, por ejemplo, se titulaban tras la asistencia obligatoria a clase, la aprobación de un examen teórico-práctico y el aprendizaje junto a agrimensores renombrados o ingenieros militares 5 .

La multiplicidad de acreditaciones y la diversidad de habilidades mostradas para su obtención en España eran un importante obstáculo para la ordenación del oficio. Así lo entendió Juan Claudio Aznar y Polanco, quien en su obra Origen de las Aguas de Madrid (1727) y basándose en unas ordenanzas para agrimensores del siglo XVII, pedía que fuera el Consejo de Castilla el único órgano con competencias en esta materia y que el permiso obtenido ante él fuera superior a los cursados por las ciudades con voto en Cortes. De hecho, en estas ordenanzas se recomendaba que dichas ciudades fueran obligadas a mantener en nómina a un agrimensor titulado por el Consejo de Castilla ${ }^{6}$. De la ausencia de una normativa y formación comunes también se lamentaba Mateo Sánchez Villajos, autor de los mejores manuales de agrimensura de la época. En su opinión, la única solución era que los agrimensores estuviesen avalados por los maestros que les hubieran enseñado el oficio. Los aspirantes a esta certificación debían tener nociones previas de agricultura y matemáticas, una reputación sin tacha, buena vista y amplia memoria. Para obtenerla también debían someterse a un examen práctico consistente en la medición de un campo grande e irregular. El documento obtenido debía permitir al nuevo agrimensor el trabajo en cualquier lugar del país, siempre que demostrase conocer las medidas locales ${ }^{7}$.

A pesar de la reputación de quienes formulaban estas propuestas, este tipo de exámenes no se generalizó, la movilidad profesional continuó siendo inexistente y mayúsculas las prevenciones ante la intervención de peritos foráneos. Se trataba de

4 DainviLle, F. (1986), «Enseignement des géographes et des géomètres», Écoles techniques et militaires au XVIIIe siècle, París, pp. 481-491; p. 489.

5 LIVA, G. (1987), «Il Collegio degli Ingegneri e Agrimensori di Milano dal '500 al primo decennio dell '800», Cartographia e Istituzioni in età Moderna, Génova, pp. 467-487.

6 Estas ordenanzas pueden verse completas en VERDEJO, F. (1796), Arte de nedir tierras, y aforar los líquidos y sólidos, Madrid, pp. 123-130. De su antigüedad no existen dudas puesto que ya aparecen comentadas en DÁvila, A. (1675), Arte de medir tierras. Excepciones de los Agrimensores, Ordenanzas para las ciudades, Villas, y Lugares de España. Noticia para trazar reloxes Orizontales, con sola regla y compás, por Geometria. Observacion del error de los Equinoccios, Valencia, capítulo I.

7 SÁNCHEZ, M. (1784), Primera y precisa geometria, o Reglas y Estadas para medir tierras, para gobierno de los Agrimensores, y Labradores, que las mensuran, deslindan, acotan, amojonan y tasan; y para aforar el vino y otras cosas, Madrid, prólogo. 
un localismo muy negativo: ciudades y villas se prevenían de este modo ante la injerencia externa, pero, en contrapartida, renunciaban a contratar a los geómetras mejor preparados. De este modo, los municipios validaban la pericia de técnicos sin formación y los hábitos y estructuras paragremiales se mantenían incólumes, como lo demuestra la formación de auténticas dinastías monopolizadoras de los empleos municipales relacionados con la agrimensura.

La ciudad de Valencia no era una excepción a esta norma, a pesar de la enorme tradición que en ella tenía el oficio de agrimensor (de soguejador o mestre de nivell $)^{8}$. Desde la Edad Media el mayor municipio del reino había solventado los problemas técnicos que se le planteaban extramuros (de los que afectaban al casco urbano se encargaba el gremio de maestros de obra, creado en 1415) con una organización que tenía su origen en un privilegio de concordia, dado por Pedro IV en 1386, en el que el consistorio y su iglesia metropolitana acordaron las condiciones para la concesión de nuevos establecimientos en el territorio de Francos y Marjales, una zona de difícil cultivo limitada por el cauce del río Turia y la Albufera9. Entre las condiciones impuestas a los beneficiarios se encontraba la obligatoriedad de cuidar de los caminos y de las acequias, motivo por el que se le dio a la ciudad la posibilidad de crear los empleos de veedor (acequiero) y de experto en agricultura para vigilar los trabajos correspondientes. Ambos quedaron desde un principio bajo la supervisión del comisario de Francos y Marjales, cargo que los concejales ocupaban de forma alterna tras ser elegidos por los jurados de la ciudad y el justicia civil. Todos estos empleos se mantenían a comienzos del siglo XVIII, momento en el que comenzaron a evolucionar ante factores como el crecimiento demográfico, la consiguiente ampliación de las zonas cultivadas y la aplicación de los decretos de Nueva Planta ${ }^{10}$.

Los comisarios comenzaron a verse implicados en pleitos cada vez más frecuentes debido a la continua apropiación de los márgenes de los caminos que realizaban los propietarios que lindaban con ellos y los asentamientos ilegales que se producían en los límites de un término mal definido ${ }^{11}$. Sobre todo porque la constante discusión

8 GLICK, T.F. (1968), «Levels and levelers: surveying irrigation in medieval Valencia», Technology and Culture, IX, pp. 165-180. Este trabajo, el primero de los dedicados al estudio de la historia de la agrimensura valenciana, fue incluido posteriormente en GLICK, T.F. (1970), Irrigation and society in medieval Valencia, Cambridge, Massachusetts, pp. 363-367.

9 Este privilegio fue confirmado por Fernando II en las Cortes de Monzón de 1510. La concordia puede consultarse completa en LLUCH, F. et al. (1991), Las acequias de francos, marjales y extremales de la ciudad de Valencia, Valencia, pp. 106-114. En la zona de Francos y Marjales se localizaban las parcelas no empadronadas por las comunidades de regantes que utilizaban las aguas sobrantes de las acequias de la huerta de Valencia conocidas como extremales. Véase al respecto GLICK (1970), pp. 44-48.

10 Toda la información que sigue, incluyendo las citas entrecomilladas, está sacada de los libros de actas del Archivo Municipal de Valencia y aparece documentada en Faus (1994).

11 El término municipal de Valencia, conocido como Particular Contribución, no estaba delimitado por completo y con precisión en el siglo XVIII, debido sobre todo a la reducción del perímetro de la 
sobre sus competencias y el procedimiento que debía seguirse para su nombramiento introducida por la aplicación del modelo castellano de corregimientos minó gravemente su autoridad ${ }^{12}$. En juego estaba discernir qué papel jugaba el municipio en el control de su propio territorio y hasta qué punto quedaba limitada su autonomía frente a los nuevos órganos de gobierno. Finalmente, aunque las ordenanzas de intendentes y las reales cédulas de corregidores y alcaldes mayores les otorgaban a todos ellos las atribuciones que tradicionalmente había desempeñado el comisario, su delegación desde 1728, ante el evidente deterioro que estaban sufriendo los puentes y los caminos del término, permitió que este último siguiera actuando. Para ello, al margen de los tradicionales empleos de veedor y experto en agricultura, se le dotó de un conjunto de ayudantes entre los que se encontraban un asesor judicial y un regidor suplente.

El cargo de veedor era el único que aparecía en las relaciones municipales con un salario anual fijo (10 libras valencianas). Sus funciones no habían cambiado desde el siglo XIII, ya que a su cargo se encontraban la visura, la composición y la limpieza de acequias, así como la distribución del agua de riego entre las comunidades de regantes. Las ejercía de forma paralela al sobrestante de la Junta de Murs $i$ Valls, que actuaba en los ámbitos de jurisdicción real ${ }^{13}$. Tampoco habían cambiado los hábitos asociados al empleo desde entonces: adscripción del hijo mayor como ayudante del titular y transmisión de los conocimientos técnicos en el seno familiar (endotecnia). Se convertía de este modo en patrimonial y se ejercía de forma ininterrumpida durante generaciones. Este empleo de acequiero adquirió gran importancia en el siglo XVIII ante la extensión del regadío (es el que con mayor facilidad se encuentra en otros municipios del Reino de Valencia), motivo por el que tendió a especializarse cada vez más. A pesar de que en Valencia el veedor siguió poseyendo la cadena mensoria con el escudo de la ciudad, en cada nuevo nombramiento se le recordaba que ya no le competía la realización de los trabajos de agrimensura y sí los relativos a la hidrometría. La misma elección de los expertos en agricultura, que desde 1238 venían actuando como ayudantes suyos, dejó de ser una atribución del veedor en 1749 , cuando fue traspasada a los alcaldes y tenientes de huerta.

Esta especialización de funciones es la que también explica que el número de expertos en agricultura se multiplicase a pesar de que la ciudad intentó limitarlo en

\footnotetext{
Albufera. Véase en este sentido LLUESMA J.A. et al. (1993), Els amollonaments de l'Albufera de València de 1577 i 1761, Valencia; y FAUS, A. (1995c), «Demarcación y cartografía de la Particular Contribución de Valencia en el siglo XVIII», Cuadernos de Geografía, 57, pp. 91-108.

12 Sobre la reorganización territorial y administrativa que siguió en Valencia a la guerra de Sucesión véase GIMÉNEZ, E. (1990), Militares en Valencia (1707-1808), Alicante.

13 La Junta de Murs $i$ Valls era un organismo municipal autónomo creado en el siglo XIV que se encargaba, sobre todo, del mantenimiento de las defensas de la ciudad ante las inundaciones del río Turia. Un acercamiento al mismo en Melió, V. (1991), La Junta de Murs i Valls. Historia de las obras públicas en la Valencia del Antiguo Régimen, siglos XIV-XVIII, Valencia.
} 
1736, cuando decidió que sólo hubiese uno de ellos por cuartel (cuatro en total) ${ }^{14}$. Esta medida pronto se mostró inviable ante la variedad de encargos que debían atender (la medición, delimitación, tasación y división de propiedades; el cuidado de los plantíos de árboles; el amojonamiento del término; etc.) y en 1744 se duplicó esta cifra. El aumento de los expertos acabó minando las bases tradicionales del empleo, que hasta mediados de siglo poseyó las mismas características paragremiales que el de veedor. El acceso al mismo de agricultores que sólo poseían vínculos de amistad o de vecindad con los antiguos titulares, así como las frecuentes quejas ante una falta de preparación que se evidenciaba en cada nuevo pleito, quebraron una trayectoria secular que lo había mantenido al margen de toda evolución.

Un momento claro de inflexión se produjo en 1751, cuando solicitó el empleo Juan Bautista Romero, sin duda el mejor experto que tuvo la ciudad en todo el siglo. El regidor que lo examinó, José Nebot, expuso en su dictamen de aprobación todas las deficiencias que eran generalizables al común de los expertos. En él se decía:

\footnotetext{
«Expone hallarse el suplicante bien impuesto en las practicas de medir areas, de quadrados, triangulos, y rectangulos, sabiendo las quatro reglas de contar, con las de los Quebrados, y Rayz quadrada, aunque todo esto lo sabia materialmente sin tener la menor noticia en la mas leve demostracion (...), lo que no dejava de ser algo arriesgado. (Parece conveniente que) se mandasse prevenir a dichos expertos, o se estableciese por punto fixo en adelante que los que solicitassen este encargo tubiesen algun baño de las primeras proposiciones de Euclides, de que supiesen copiar algunas figuras y al mismo passo obligarles a que midiesen con cuerda de veinte brazas como estava en los fueros (...)».
}

La solicitud del establecimiento de una prueba como fórmula de acceso al empleo chocaba con la preparación habitual de los expertos, que se reducía a saber leer, escribir y contar. Estas cualidades, nada desdeñables en una sociedad rural, eran insuficientes ante las nuevas exigencias del oficio. Por este motivo, mientras la mayoría de ellos acabaría dedicándose en exclusiva a la tasación de terrenos, función que también pudieron ejercer en el casco urbano a partir de 1786, los pocos que tuvieron acceso a una enseñanza regulada reivindicaron el título diferenciado de agrimensor. Este empleo ya había sido creado en Valencia en 1737, cuando el catalán Antonio Cuyás pasó un examen para el puesto después de trabajar dos años como experto y denunciar ante el consistorio municipal las deficiencias del empleo. La prueba que verificó ante el impresor y matemático Antonio Bordázar era muy semejante a la recomendada por Sánchez Villajos:

«Lo primero le he examinado de arithmetica y le he hallado diestro en las 4 reglas de enteros y quebrados, reglas de tres simples y compuestas y sacar raices que es operasion fre-

\footnotetext{
14 La Particular Contribución de Valencia estaba dividida en cuatro cuarteles: Benimaclet, Russafa Patraix y Campanar.
} 
quente en los agrimensores. Lo segundo le he examinado de Geometria Practica no solo plana sino tambien esterometrica porque aunque agrimensor solo dice medir de campos que pertenece a la Geometria y por consiguiente de planos, puede y suele aver de medir algunos terrenos solidos para saber el numero de cargas y coste de diferentes fabricas y otras obras publicas (...). Lo tercero le he hecho exercitar un terreno irregular (...). He hecho para mayor prueba y examen que calculasse ó midiesse un terreno que llaman inasecible esto es un campo o huerto que no puede penetrarse (...)».

Sin embargo, cuando tras la muerte de Cuyás en 1743 el cargo pasó a su hijo Carlos y éste lo abandonó, la ciudad no se planteó la necesidad de cubrirlo dado que por entonces las diferencias entre los expertos tradicionales y los agrimensores aún no estaban bien definidas. El cargo quedó vacío hasta 1762, cuando fue ocupado por Mariano Castillo tras presentar credenciales de sus estudios universitarios y de sus trabajos para el intendente del reino. Fue entonces cuando las discusiones sobre la diferente preparación que debían poseer los expertos y los agrimensores que trabajaban para la ciudad se multiplicaron. La presentación de nuevas solicitudes para ocupar el empleo por parte de José Rispo y Tomás Casanova acabó de convencer al consistorio de la necesidad de pedir un informe al respecto. Las conclusiones del mismo no pudieron ser más elocuentes:

\footnotetext{
«Con motivo de ser frequente la necesidad de haver de passar expertos a medir y hazer vista de ojos en los Campos, tassar el justo valor de ellos, señalar sus verdaderos lindes, desidir questiones entre los Labradores sobre el usso de las aguas, sendas, regaderas, y ottras cosas, que requerian una particular inteligencia y aplicacion, de cuya falta se originan innumerables Pleytos, por la impericia de algunos especialmente en lo tocante a la Geometria, Geografia , Idrometria; lo que podia atajarse con que nuevamente se nombrassen Agrimensores peritos en esto, sugetandoles al exsamen de dichas tres ciencias: suplicaron a esta Ciudad (el síndico José Huguet y los electos de los cuarteles de la Particular Contribución) se sirviesse señalar examinadores, a fin de que abierto el examen declarassen las Personas Peritas y haviles para dichos encargos, y en vista de ello, nombrarles con Titulo particular (...)».
}

Esto es, fueron los mismos alcaldes y tenientes de huerta a quienes correspondía el nombramiento de expertos quienes instaban al pleno municipal a recuperar el empleo diferenciado de agrimensor previa instauración de una prueba de acceso. Su solicitud fue aprobada tras dar el visto bueno Francisco Benito Escuder, nuevo procurador general, quien recomendó el nombramiento de cuatro agrimensores por cuartel. Se abría de este modo un resquicio en la estructura paragremial vigente desde el siglo XIV, ya que al exigirse mayores conocimientos y un examen previo, la experiencia resultaba insuficiente. Considerando que ahora había que acudir a instituciones docentes o al magisterio de personas de reconocido prestigio, los cauces de acceso al empleo se modificaban con claridad.

El ayuntamiento comisionó al propio Escuder para que formase los capítulos que debían regir el examen y la actuación de los agrimensores titulados. Sin embargo, no 
fue necesaria su redacción porque la ciudad delegó esta función en un organismo creado en 1768 bajo su patrocinio: la Real Academia de Bellas Artes de San Carlos. Al margen de Rispo y Casanova, entre 1762 y 1768 el consistorio sólo nombró a dos nuevos agrimensores: Francisco Aparisi y José Soto. El primero se había formado junto al jesuita Antonio Eximeno, lo que le eximió de cualquier prueba, mientras que el segundo pasó el examen preceptivo ante los catedráticos de matemáticas de la Universidad de Valencia Rafael Lassala, Vicente Capera y Gaspar Pérez.

\section{AnTECEDENTES de la Real ACAdEMia de Bellas ARTES de SAN CARlos}

Que la agrimensura quedase finalmente en manos de una academia consagrada a las bellas artes no fue, en absoluto, producto de la casualidad. El academicismo poseía una gran tradición en la ciudad de Valencia desde el siglo XV (cuando las academias se conocían como parlaments o col.lacions) y, aunque desde sus orígenes quedó vinculado a los ambientes literarios, siempre mostró un gran interés por los avances científicos y su aplicación práctica. La Academia de los Nocturnos (1591-1594), fundada a imitación de las italianas y modelo, a su vez, de las valencianas del siglo XVII (redacción de estatutos para regular su funcionamiento, máxima jerarquización de los cargos, utilización de pseudónimos por sus miembros, reuniones regulares en casas particulares, etc.), puede servirnos de ejemplo. En sus actas se incluyen sesiones sobre zoología, botánica, mineralogía, matemáticas y, sobre todo, medicina. Sobre un total de cerca de 400 citas (la mayoría de autores clásicos y de contenido religioso y/o filosófico), un $12 \%$ son científicas ${ }^{15}$.

Este discurso enciclopédico fue característico de las academias barrocas valencianas y culminó con la creación de algunas dedicadas en exclusiva al campo de la ciencia. Entre 1591 y 1705 existieron 24 academias en Valencia (considerando reales y ficticias, ordinarias y de ocasión), aunque la mayoría se fundaron a partir de 1665 y fue en esa época cuando se dieron las más importantes: la del Alcázar, la Matemática y la Valenciana ${ }^{16}$. Las científicas surgieron a partir de tertulias extrauniversitarias y convirtieron a la ciudad de Valencia en uno de los principales centros del movimiento novator español ${ }^{17}$. Este ambiente tuvo su corolario en el proyecto de Academia

\footnotetext{
15 RODRÍGUEZ, E. (1993), «Del saber cenacular a la Ilustración: el borrador enciclopédico de la Academia de los Nocturnos», De las academias a la Enciclopedia: el discurso del saber en la modernidad, Valencia, pp 27-68; p. 61

16 MAS, P. (1993), «Academias valencianas durante el Barroco», De las academias a la Enciclopedia: el discurso del saber en la modernidad, Valencia, pp. 171-224.

17 La bibliografía sobre este periodo en Valencia es muy amplia. Son de imprescindible lectura: PESET, V. (1966), «La Universidad de Valencia y la renovación científica española», Boletín de la Sociedad Castellonense de Cultura, 42, pp. 70-99; GARCíA, S. (1968), Els fonaments del País Valencià modern, Valencia, pp. 147-169; LÓPEZ, J. Mª (1969), La introducción de la ciencia moderna en España, Barcelo-
} 
Matemática de Antonio Bordázar (1740-1741) y la creación de la Academia de Santa Bárbara (1753-1761). Se convirtió, de este modo, en el puente entre las academias áureas del siglo XVII y las plenamente institucionalizadas del siglo XVIII ${ }^{18}$.

Al margen de las literarias (del Parnaso, del Alcázar, etc.), que continuaron tratándolos, seis fueron las academias en las que se discutieron temas científicos y sirvieron para congregar a los novatores valencianos: la del carrer del Bisbe, creada en 1685 bajo el mecenazgo y la presidencia del conde de Alcudia (conocida también como de Nuestra Señora de los Desamparados y el Patriarca San José); la de Matemáticas que se reunió en el domicilio de Baltasar de Íñigo a partir de 1687; la que en esas fechas se celebraba en casa de Félix Falcó; la congregada desde 1690 en casa de José Castellví Corona, marqués de Villatorcas, y luego en la del nuevo conde de Alcudia (llamada de Nuestra Señora de los Desamparados y San Francisco Javier); la que acogió en su biblioteca Juan Basilio Castellví, conde de Cervellón y nuevo marqués de Villatorcas, hacia 1699; y la postrera que tuvo lugar a partir de 1719 en una alquería de la huerta bajo la dirección de Vicente Albiñana ${ }^{19}$.

Por estas tertulias o academias pasaron, además de personajes tan importantes en la Valencia de la época como los historiadores Manuel Martí y José Manuel Miñana, el bilbiógrafo José Rodríguez o el jurista Pedro Borrull, todos los miembros del movimiento novator, desde José Vicente del Olmo o Félix Falcó, discípulos declarados de José Zaragoza, hasta los máximos representantes del mismo: Baltasar de Íñigo, Tomás Vicente Tosca y Juan Bautista Corachán. Las reuniones les sirvieron para dar forma a una comunidad científica todavía embrionaria empeñada en la introducción, la asimilación y la difusión de la ciencia moderna en España. En ellas se debatió sobre temas relativos a la esfera, los meteoros, la perspectiva, las observaciones astronómicas o la arquitectura militar, sin la rigidez que imponían las clases universitarias y sin perder de vista en ningún momento la necesaria vinculación de las academias con la sociedad de su tiempo. Esta apertura de miras es la que justifica que el interés por la técnica y las aplicaciones prácticas de la ciencia estuvieran siempre presentes en sus sesiones.

Fuera de las academias, el carácter abierto de los novatores se tradujo en una gran implicación por su parte en los problemas que afectaban a la ciudad. Lejos de la imagen del científico solitario y algo huraño, todos ellos se emplearon en encargos relacionados con sus conocimientos. No hay mejores ejemplos en este sentido que los de Tosca y Corachán, vicerrector y catedrático de matemáticas, respectivamente, de la Universidad de Valencia. Ambos desarrollaron fuera de las aulas universitarias una

na; y NaVArro, V. (1985), Tradició i canvi científic al País Valencià modern, Valencia. Las conclusiones de estos estudios, dilatados a lo largo de treinta años, han sido compiladas en LóPEZ, J. Ma et al. (1998), La actividad científica valenciana de la Ilustración, Valencia, I, pp. 17-45.

18 Álvarez, P. (1993), «Las academias de los novatores», De las academias a la Enciclopedia: el discurso del saber en la modernidad, Valencia, pp. 263-300; p. 271.

19 LóPEZ et al. (1998), pp. 25-26. 
labor ingente que incluía la docencia privada, la elaboración de proyectos y la ejecución de trabajos con cargo a los presupuestos de la ciudad, y la redacción y publicación de obras con vocación divulgadora que pusieron al alcance de diferentes colectivos profesionales la preparación matemática que requería su oficio. Baste recordar desde el punto de vista que nos interesa que el propio Antonio Cuyás, primer agrimensor titulado por la ciudad, fue alumno de Tosca; que el Compendio Mathematico de éste (1707-1715) y la Arithmetica demonstrada de Corachán (1735) conocieron diversas reediciones a lo largo del siglo XVIII y fueron las obras más citadas en los manuales de agrimensura; o que a ellos se debieron trabajos para la Junta de Murs $i$ Valls, proyectos para la construcción de un puerto en Cullera y la canalización de los ríos Turia y Júcar, inspecciones de las instalaciones del Grau de Valencia e, incluso, el plano de la ciudad que Tosca levantó en $1704^{20}$.

El contacto de los novatores con los expertos en agricultura y los maestros de obra fue una constante ${ }^{21}$. No puede extrañarnos, por tanto, que nos hayan dejado multitud de escritos en los que criticaban la escasa preparación de estos técnicos y, al tiempo, hacían propuestas para mejorarla, o que tanto las clases que Tosca impartía desde 1697 en sus aposentos de la Congregación de San Felipe Neri como las conferencias que Corachán daba al margen de su cátedra estuvieron abiertas a discípulos no universitarios.

Todas estas inquietudes confluyeron en la persona de Antonio Bordázar. Discípulo de los novatores, en él se dieron dos cualidades que le permitieron, sin ser un científico de talla, integrarse y participar del ambiente de renovación que existía en Valencia. De un lado, su interés por la enseñanza de las matemáticas; de otro, su condición de impresor. La primera de estas cualidades le llevó a plantear el proyecto más ambicioso de mediados de siglo: la creación de una Academia de Matemáticas abierta a los civiles. La segunda, a poner su imprenta al servicio de sus maestros: de ella salieron, por ejemplo, el Compendio de Tosca y la Arithmetica de Corachán. Este interés por la difusión y la aplicación de los nuevos conocimientos científicos hizo de Bordázar un preilustrado en sentido estricto.

De Bordázar se conservan varios manuscritos científicos de un valor discreto (unas Recreaciones Matemáticas a imitación de las de Jacques Ozanam, un Diccionario Facultativo inconcluso, etc.) y algunas obras que él mismo publicó (la Puntual Relación de la riada del Turia de 1731, la Proporción de Monedas, Pesos i Medidas

20 FAUS (1995a), pp. 53-59. Detalles concretos de algunos de estos trabajos en Albiñana, S. y HERNÁNDEZ, T. M. (1983), «Notas sobre técnica y proyectismo en la Albufera y el Júcar en la Edad Moderna», Estudis, 10, pp. 55-90; y AlBiÑANA, S. y HeRnÁNDEZ, T. M. (1984), «Técnica e Ilustración en Valencia. Los proyectos portuarios», Saitabi, 34, pp. 125-151.

21 Para el caso de estos últimos véase HERNÁNDEZ, T.M. (1987), «Els novatores i els mestres d’obra de València (1675-1740)», Afers, 5/6, pp. 421-465. El caso mejor conocido es el contacto continuo que mantuvo Tosca con los maestros de obra debido a su afición por la arquitectura. A él se debieron, por ejemplo, las trazas de la Casa de las Comedias, de la Puerta del Real y la fachada de la Iglesia de Santo Tomás, todas ellas en Valencia. OREllanA, M.A. (s.f.), Biografía pictórica valentina, Valencia, p. 315. 
de 1736, el Parecer sobre el cometa de 1744, etc.). Sin embargo, el aspecto más sobresaliente de su trayectoria es el énfasis que siempre puso en la necesidad de mejorar la preparación de los técnicos que le acompañaban en los trabajos prácticos que también realizó. Aunque no es posible detallarlos aquí, baste decir que entre estos se encontraban numerosas visuras con motivo de pleitos que se seguían ante la Real Audiencia de Valencia y, sobre todo, una gran actividad cartográfica que le llevó a actualizar el plano urbano de Tosca antes de que fuera llevado a la imprenta por José Fortea y a levantar otro paralelo de la Particular Contribución ${ }^{22}$.

Las gestiones que Bordázar inició en 1733 para la creación de una Academia de Matemáticas no tendrían sentido sin el poso dejado por el academicismo novator y la actividad práctica desarrollada por sus maestros y por él mismo ${ }^{23}$. En ese año se dirigió a Gregorio Mayáns para pedirle información sobre el funcionamiento de la Academia de las Ciencias de París y, en particular, sobre las características de la práctica docente y las circunstancias económicas y políticas que habían permitido su creación. Tras comprender que un proyecto de esta magnitud no era posible sin contar con grandes apoyos, puso en marcha sus contactos (Bordázar era impresor oficial de Valencia y del Santo Oficio de la Inquisición). Contactó con el conde de Carlet, regidor perpetuo de la ciudad, le rogó al propio Mayáns para que intercediese por él ante el marqués de la Compuesta y el ministro José Patiño, escribió al duque de Montemar, ministro de la Guerra, y buscó, finalmente, la protección del infante Felipe. A pesar de que incluso publicó su Idea de una Academia Mathematica (1740) bajo la advocación de este último, el momento no era el más adecuado. Las circunstancias políticas internacionales y la consiguiente necesidad de conocer con exactitud el territorio nacional, además del propio desarrollo tecnológico del ejército, aconsejaban a la Corona la apertura de centros para la formación de militares.

Bordázar pudo comprobarlo personalmente cuando se le instó a que esperase a la apertura de la Academia Militar de Barcelona. Sintiéndose desplazado tras la llegada a Valencia del ingeniero Mateo Calabro, respondió que la suya debía abrirse a los civiles y, mientras tanto, acogió a una decena de alumnos en su casa y en la de Manuel Gómez Marco, alumno de Tosca que era catedrático de Filosofía y vicario de la iglesia parroquial de San Pedro. Al tiempo, consiguió la intercesión del conde de Carlet para que la ciudad le cediera una sala donde celebrar conferencias de matemáticas (se habilitó para ello el salón del Consell General). Aunque la academia inició finalmente su andadura en 1740, lo hizo sin tener en cuenta los consejos de Bordázar, que al año siguiente se desvinculó por completo de ella y la dio por fracasada.

22 Un estudio de la obra científica de Bordázar, así como de sus actuaciones prácticas, en Faus (1995a), pp. 59-81.

23 Sobre este proyecto véase NAVARRO, V. (1973), «Noticia acerca de Antonio Bordázar y la fundación de una Academia Matemática en Valencia», I Congreso de Historia del País Valenciano, Valencia, III, pp. 589-595. Noticias complementarias en Faus (1995a), pp. 69-72. 
El proyecto de Bordázar había sido respaldado, al margen de Gómez Marco y el conde de Carlet, por la firma de personas muy influyentes en la ciudad. Entre ellas se encontraban Juan Bautista Corachán, José Bou, el médico Andrés Piquer, el maestro de obra José Herrero, y el teólogo Vicente Calatayud. Todos ellos comprendieron los beneficios que se derivarían de la misma y fueron conscientes de su necesidad. Desde el punto de vista que estamos tratando, el impresor no podían ser más claro:

«(...) Con que grave perjuicio no se valiera la Republica (de las artes comunes) en el repartimiento de las aguas, division de los campos, assignacion de las jurisdicciones i territorios i otras disposiciones del publico, por la ignorancia de los que llaman Peritos, no pudiendo ser sin el estudio de la Hidrometria, Geodesia, Geografia i otras» ${ }^{24}$.

Aunque Bordázar pasó a colaborar inmediatamente con la Academia Valenciana que puso en marcha Gregorio Mayáns en 1742 (publicó sus Constituciones, cedió su casa para las primeras reuniones y aconsejó al erudito de Oliva sobre los libros de matemáticas que debía adquirir) la auténtica continuadora de este proyecto fracasado fue la Academia de Santa Bárbara ${ }^{25}$. Prueba de ello es que algunos de los firmantes de la Idea de Bordázar formaron parte de la junta que creó esta nueva academia y que uno de ellos, el propio Manuel Gómez Marco, ocupó el cargo de secretario (también fue administrador de la academia de Mayáns). Además, Rafael Lassala y Vicente Capera, catedráticos de matemáticas a quienes hemos visto examinando a los aspirantes al empleo de agrimensor municipal, fueron nombrados académicos supernumerarios de honor y mérito en la clase de arquitectura. Nada de esto puede extrañarnos ya que la arquitectura civil y militar siempre estuvo presente en las tertulias y las obras de los novatore ${ }^{26} \mathrm{y}$ era una de las materias que Bordázar pensaba abordar en su academia en unión de otras como la aritmética, la geometría o la perspectiva.

En la Breve noticia que Gómez Marco escribió en 1757 para dar cuenta del proceso de creación de la Academia de Santa Bárbara lo justificaba, entre otras razones, por la necesidad de perfeccionar el dibujo en todas las ramas de la ciencia. De esta manera, la nueva academia trascendía el campo de las bellas artes y se vinculaba al ambiente de renovación científica existente en Valencia:

«(...) Las Academias de las Bellas Artes no son establecimientos que sirven a la pompa, ostentación, y entretenimiento, sino al bien público. (...) la Física experimental no puede aprenderse sin el socorro de Dibuxos, que pongan a la vista, o las máquinas para sus experimentos, o los usos de ellas. Todas las partes de las Matemáticas, Geometría, Hidráulica, Ar-

24 BordázAr, A. (1740), Idea de una Academia Mathematica dirigida al serenisimo señor Don Felipe infante de España, Valencia, p. 20.

25 El mejor estudio de la Academia de Santa Bárbara de Valencia está contenido en Bérchez, J. (1987), parte I.

26 El volumen I del Compendio de Tosca, donde se hace referencia a ella, fue reeditado de manera independiente en 1794, lo que da idea de su utilidad. 
quitectura civil y militar, Astronomía, Náutica y Geografía fundan sus problemas, o demostraciones en el buril. La Anatomía y Botánica, a falta de inspección de los cadáveres, o plantas, nada enseñan sino por estampas, y para los profesores de todas estas Ciencias es muy provechoso una Academia: aprendiendo en ella a dibujar el Filósofo, Matemático, Anatómico, o Botánico, en un nuevo descubrimiento delinean por sí lo que con dificultad pueden dar a entender a otro dibujante» ${ }^{27}$.

La relación entre las bellas artes y la enseñanza de las matemáticas siempre estuvo presente en la Academia de Santa Bárbara. Al margen de la presencia de Lassala y Capera, baste recordar en este sentido que la sala que se utilizaba por las tardes para las clases de dibujo de escultura y la delineación arquitectónica era la misma que por las manañas se empleaba para la enseñanza universitaria de las matemáticas, motivo por el que estaba decorada con láminas de los Elementos de Euclides ${ }^{28}$. Además, la docencia que se impartía en ellas solía basarse en materias relacionadas con la técnica y entre los alumnos se encontraban numerosos maestros de obra y canteros que, dado que no poseían el título de arquitecto, firmaban sus encargos como profesores de matemáticas ${ }^{29}$.

La Academia de Santa Bárbara se mantuvo hasta 1761 gracias a unos locales que le cedió la ciudad y a la ayuda económica prestada por el intendente del reino y el arzobispo. Cuando este patrocinio se demostró insuficiente y el centro tuvo que cerrar, algunos de sus miembros se dirigieron a la Real Academia de Bellas Artes de San Fernando con el fin de obtener el grado de académicos de mérito. Dos de ellos, los arquitectos Vicente Gascó y Felipe Rubio, presentaron un memorial al año siguiente en el que solicitaban la creación de otra academia en Valencia que sustituyera a la de Santa Bárbara. La ciudad hizo lo propio ante el rey y cedió 30.000 reales en concepto de ayuda. El proyecto, sin embargo, se paralizó debido a los gastos ocasionados por la construcción del Camino Real de Madrid y por las suspicacias que provocaba entre los académicos de San Fernando la extensión del patrocinio real a academias provinciales. No se recuperaría hasta 1765 , cuando una junta elaboró los estatutos de la nueva academia, bautizada como de San Carlos. Aunque ésta no era una simple continuación de la de Santa Bárbara (ligada al academismo barroco), desde el punto de vista que nos interesa no existían grandes diferencias entre ellas, ya que las dos se crearon bajo el patronazgo municipal y estuvieron al servicio de la ciudad.

27 GómEZ, M. (1757), Breve noticia de los principios y progresos de la Academia de pintura, escultura y arquitectura erigida en la Ciudad de Valencia bajo el título de Santa Bárbara, y de la proporción que tienen sus naturales para estas bellas artes, Madrid, pp. 24-25.

28 BÉRCHEZ (1987), pp. 71-73.

29 Véase a este respecto ALBIÑANA, S. (1982), «Francisco Ballester y la enseñanza de las Matemáticas en la Universidad de Valencia (1745-1752)», Estudios dedicados a J. Peset Aleixandre, Valencia, pp. 65-77; p. 75. 


\section{La AGRIMENSURA EN VALENCIA TRAS LA CREACIÓN DE LA REAL ACADEMIA DE BELLAS ARTES DE SAN CARLOS (1768-1808)}

La creación de la Real Academia de Bellas Artes de San Carlos proporcionó a la ciudad la oportunidad de asegurar la preparación de los peritos que la servían y de delegar su titulación en una entidad directamente relacionada con ella ${ }^{30}$. Dados los antecedentes del academicismo novator, poco puede extrañarnos esta decisión. De hecho, los mismos estatutos de esta nueva academia ya recogían, como única novedad respecto de los de la Real de San Fernando de Madrid que le habían servido de modelo, claras referencias a la necesaria aplicación práctica de los conocimientos científicos. Así se indicaba en ellos, por ejemplo, la obligatoriedad de pasar un examen para obtener el título de arquitecto:

«Es mi voluntad que todos los que desde el presente dia en adelante hayan de egercer la arquitectura, y señaladamente el medir, tasar, idear y dirigir fábricas, han de ser precisamente habilitados por la Academia y no por otro Tribunal, Magistrado, Gremio, ni persona alguna precediendo un riguroso examen hecho en Junta ordinaria, no solo de la teórica de la Arquitectura, sino tambien de la práctica de la Geometría, Aritmética, Maquinaria y demás ciencias matemáticas necesarias para hacer con acierto unas operaciones en que tanto se interesan mis vasallos» ${ }^{31}$

Como organismo que debía monopolizar la expedición de los títulos librados hasta entonces por gremios, municipios y tribunales ${ }^{32}$, la Academia de San Carlos se convirtió en el instrumento más adecuado para conseguir la mejora técnica pedida desde el consistorio. Por esta razón, es lógico que dicho monopolio se extendiera también a la agrimensura, no sólo porque la ciudad tenía el patronato sobre la academia y sus ediles detentaban diferentes cargos en ella, sino porque la etapa fundacional de ésta (1762-1768) coincidió con los años en los que el consistorio municipal se debatía en un mar de dudas, discusiones y dictámenes sobre el empleo de agrimensor.

El modelo de examen pensado para arquitectos y maestros de obra sirvió igualmente para los agrimensores, entre otros motivos porque fueron los directores y los tenientes de arquitectura de la academia quienes se encargaron de ejecutarlo. Los estatutos recogían la necesidad de superarlo para todo nuevo profesional, pero también incluían cláusulas que permitían el acomodo a la situación de los titulados con anterioridad. En el caso de los maestros de obra, se les concedía un plazo de seis meses para verificar la prueba, pero, al tiempo, se recomendaba que ésta se efectuase

30 Sobre el proceso de creación de la Academia de San Carlos y su historia véanse Bérchez (1987), parte II; y Aldana, S. (1998), La Real Academia de Bellas Artes de San Carlos de Valencia. Historia de una institución, Valencia, pp. 35-41.

31 Estatutos de la Real Academia de San Carlos (1828), Valencia, apartado XXI, 7.

32 Estatutos (1828), apartado XXXI, 5. 
con amor y suavidad y que se establecieran los cursos necesarios para los aquellos que no la pasasen ${ }^{33}$. En el de los agrimensores se iba aún más lejos, puesto que se reconocían los títulos ya existentes:

\footnotetext{
«Asimismo mando, que de hoy en adelante solo puedan egercer la profesion de Agrimensores y Aforadores los que la Academia examinare y aprobare en la Geometría y Aritmética necesaria para el egercicio de estos ministerios; pero no es mi voluntad que cesen en ellos los que con la solemne aprobacion que se daba hasta aquí los estén egerciendo» ${ }^{34}$.
}

Este diferente tratamiento puede explicarse por el origen de la academia. Como anexa al municipio, debía ratificar los nombramientos realizados por él, mientras que como entidad que debía asegurar la supeditación de los oficios artísticos a reglas y principios uniformes, su actuación estaba dirigida a la eliminación de las barreras gremiales. El establecimiento de un examen de capacitación podía ser una novedad y una posibilidad de reconocimiento público para los agrimensores, pero suponía un ataque directo a las estructuras vigentes en oficios como el de maestro de obra.

Las pruebas correspondientes se iniciaron en el verano de 1768, si bien pocos meses antes ya habían obtenido su aprobación algunos maestros de obra: José Herrero, Francisco Cabrera, Vicente Piño, Juan Bautista Mínguez y Lorenzo Martínez ${ }^{35}$. Este último y Mauro Minguet también superaron en esa fecha el examen de agrimensor, por lo que fueron los primeros titulados académicos en este campo. Desde entonces las convocatorias dependieron de la presentación de solicitudes, no existiendo una fecha determinada para este fin hasta 1808, cuando se habilitaron todos los jueves que fueran primeros de mes.

El que se reconociesen a los agrimensores los títulos anteriores justifica el distinto ritmo de aprobados entre 1768 y 1808. Durante estas cuatro décadas obtuvieron la certificación académica poco más de trescientas personas, un tercio de las cuales eran foráneas al Reino de Valencia [ANEXO]. De ellas, apenas el 16\% se examinó antes de 1790 y durante cuatro años (1768-1771) sólo lo hizo Tomás Casanova, agrimensor de la ciudad y miembro de la Real Sociedad Económica de Amigos del País de Valencia. La generalización de las pruebas en la última década del siglo se explica por el acceso al empleo de nuevos peritos y el creciente prestigio de la Academia de San Carlos. De otro lado, la procedencia geográfica de los titulados era del todo lógica: los valencianos provenían en su mayor parte de comarcas con alta densidad demográfica y grandes problemas técnicos relacionados con el regadío (Planas Alta y Baixa, l'Horta, l'Alacantí, ambas Riberas, el Baix Vinalopó, el Bajo Segura, la Coste-

33 Estatutos (1828), apartado XXXI, 9

34 Estatutos (1828), apartado XXX, 5.

35 Los datos que siguen sobre los exámenes realizados a agrimensores están basados en la documentación existente en los archivos de la Real Academia de Bellas Artes de San Carlos y el Municipal de Valencia y su procedencia concreta está detallada en Faus (1995a), pp. 107-129. 
ra y el Camp de Morvedre), mientras que los foráneos lo hacían en un 95\% de las actuales provincias de Albacete (casi el 50\%), Cuenca y Murcia. La distancia jugaba un papel importante en esta distribución, pero más que ella lo hacía la red de comunicaciones (es significativa en este sentido la ausencia de titulados de la comarca de la Safor) y, en el caso de los foráneos, la competencia de otras academias.

Pueden distinguirse cuatro grupos de aspirantes:

a) Nuevos peritos procedentes del mundo rural, que llegaban al oficio confiados en los conocimientos de aritmética y geometría elementales obtenidos trabajando junto a los expertos y agrimensores municipales. Es el caso más común entre los valencianos, pudiéndose tomar como ejemplos característicos los de Juan Bautista Alvarez, Antonio Casas o Roque Girona, labradores contratados en las obras de prolongación de la Acequia Real del Júcar con anterioridad a su titulación.

b) Expertos de pequeños municipios, que iban a la academia para convalidar su titulación. Este era el contingente más numeroso entre los foráneos, que en las solicitudes de examen solían hacer constar su trabajo antecedente a nivel local. Es el caso, por ejemplo, de José Torres o Antonio García, quienes indicaban en sus memoriales que poseían certificaciones expedidas por los justicias de sus villas respectivas.

c) Hijos de expertos y agrimensores que ejercían antes de que se crease la academia o se titularon en ella. Era común que reseñasen sus vínculos familiares y su trabajo junto al perito ya aprobado para reforzar la solicitud. En esta situación se encontraban, por ejemplo, Pedro Pablo Olmos, Vicente Casanova, Tomás Coltell o Miguel Cuenca.

d) Militares de baja graduación y personas relacionadas con el ejército, que por su cercanía a los ingenieros militares y la formación recibida poseían los conocimientos mínimos requeridos. Se trataba de profesionales con destino circunstancial en el Reino de Valencia, lo que explica la diversidad de provincias de origen. En esta posición se hallaban Francisco Fernández de Prado, contralor provincial de artillería jubilado, los sargentos Lorenzo Moreno y Tomás Antonio García, el cabo primero Vicente Núñez o los soldados Ramón Fernández Blanco y José Carra.

El examen que todos ellos debieron aprobar era, en gran medida, un simple trámite burocrático. Consistía en preguntas orales sobre aritmética y geometría elementales, resueltas ante los académicos de arquitectura comisionados al efecto. A diferencia de las planteadas a los maestros de obra, que fueron uniformadas con las de la Academia de San Fernando en 1787, estas pruebas eran originales en España. No se ha conservado ningún documento cartográfico de las mismas, por lo que las prácticas debían reducirse a la resolución de operaciones matemáticas. La teoría, por su parte, 
podía soslayarse en función de la experiencia demostrada por el aspirante. Esta flexibilidad explica que el primer suspenso no se produjese hasta 1801 y que el agrimensor afectado (Bautista Andrés, de Soneja) fuese aprobado un mes más tarde. Posiblemente aquí radique la causa de las limitaciones que la propia academia introdujo en el uso de la titulación: a partir de 1784 la aprobación excluía, salvo que se indicara lo contrario, la idoneidad del aspirante para el levantamiento de mapas y planos y las prácticas de nivelación. De este modo, comenzó a distinguirse entre quienes se examinaban a petición propia de estas materias (o hidrómetras) y la inmensa mayoría de los titulados, que vieron circunscrito su campo de actuación a la medición de tierras.

Esta última decisión se relaciona también con las competencias asumidas por los arquitectos de la academia, entre las que se incluían la admisión de todos los proyectos de obra que pensaban ejecurtarse en el reino, incluyendo la comprobación de los planos que los recogían. Aunque era una prerrogativa que afectaba más a la competencia que mantenían con los ingenieros militares, el que los agrimensores quedasen al margen de determinados encargos no hacía sino delimitar las funciones de unos y otros. En realidad, las presiones de la ciudad habían colocado en una difícil situación a la academia. Como responsable de la expedición del título de agrimensor debía participar en la consolidación de una actividad ajena a las bellas artes, mientras que como centro educativo no podía sino velar por los intereses de sus arquitectos. La agrimensura acabó convirtiéndose, por este camino, en una obligación a la que se prestaba una atención mínima.

La ausencia de cursos específicos para agrimensores dentro de la academia tuvo que ser cubierta por los propios titulados, que en más de una ocasión abrieron centros privados $^{36}$. Por este motivo, es frecuente leer en las solicitudes de examen el nombre del agrimensor con el que el aspirante había preparado la prueba. Así, José Ruiz confesaba haber estudiado con José Rico; José Calatayud, con Juan Fenoll; Francisco Cuesta, con Antonio López; etc. A veces se incluía el de algún académico, como en el caso del asturiano Ramón Fernández Blanco, que se declaraba discípulo de Manuel Blasco. Algunos otros (Miguel Cuenca, Antonio Herráez o José Polo) podían, en fin, haber acudido a las clases de geometría destinadas a los arquitectos y, por esta razón, se presentaban como alumnos de la academia.

El desinterés hacia la agrimensura por parte de los académicos de San Carlos se refleja también en la escasa atención prestada a la defensa de los titulados. A diferencia de los maestros de obra, cuyos derechos profesionales se difundieron de forma inmediata, los que afectaban a los agrimensores no conocieron tanta publicidad. Su desconocimiento y el ejercicio de la profesión por parte de quienes poseían una titulación anterior a 1768 generaron no pocos enfrentamientos ante los que la academia reaccionó tarde y

36 Como en el caso de Manuel Ortiz de Zárate, quien tras obtener el título en 1791 y antes de ser nombrado agrimensor de Alicante en 1796, fundó una Academia de Matemáticas en esta ciudad junto a su hijo Andrés. Faus (1995a), p. 114. 
mal. A pesar de que existían listas impresas de aprobados, la actuación de expertos en encargos propios de agrimensores fue constante durante lo que restaba de siglo.

Resulta significativo comparar esta situación con la que vivían los maestros de obra y los arquitectos, que sí vieron defendido su trabajo de la competencia ilegal. Nada mejor para ello que recurrir a las palabras autobiográficas de Vicente Cuenca, arquitecto de Xàtiva que era hijo de un agrimensor titulado, para comprobar las dificultades que encontraban quienes pretendían ejercer al margen de la academia:

\footnotetext{
«Como no tenía título alguno para hacer dichas obras salían enemigos ya de Valencia, ya de esta Ciudad (Xàtiva), que no dejavan de incomodarme queriendome privar del exercicio de mi facultad; efectivamente lo consiguieron, pero tomando la mano la Ilustre ciudad, ésta sacó la licencia y beneplazito de mis superiores para trasladarme a Madrid y sacar el título de Arquitecto. Por el año 1800 fui a Madrid y después de los rigurosos examenes obtuve el título de Arquitecto (que poseo) de la Real Academia de San Fernando, en 1 de Marzo de 1801. Constituido en esta de San Felipe (Xàtiva) con el nuevo titulo y con el mismo objeto que hantes, todos los contrarios enmudecieron y serenó la tempestad. Empezaron de nuevo los encargos (...)»37.
}

Este diferente comportamiento de la academia con respecto a los agrimensores y los maestros de obras es comprensible. Enfrentada al sistema gremial desde su creación, debía defender sus enseñanzas en cuantas ocasiones tuviera. De este modo, la agrimensura, que había sido beneficiada en la redacción de sus estatutos, se encontraba marginada en su aplicación. No lo hubiese sido tanto si los municipios no hubiesen persistido en mantener sus privilegios en esta materia. Una década después de la creación de la Academia de San Carlos, el consistorio de la ciudad de Valencia seguía, como en el caso de Juan Bautista Alvarez, verificando la aptitud de quienes demandaban el empleo de agrimensor, tuviesen o no la aprobación académica. No puede extrañarnos que otros, como el de Alicante, se limitasen a registrar en sus actas las titulaciones académicas que presentaban los aspirantes al empleo, o que, como el de Segorbe, siguieran sin distinguir entre agrimensores y expertos a finales de siglo.

La situación no era muy distinta de la que más tarde se produjo en Valladolid y Zaragoza tras crearse la Academia de Matemáticas y Nobles Artes ${ }^{38}$ y la Academia de San Luis ${ }^{39}$, respectivamente, lo que demuestra que quizá la solución adoptada no era la más adecuada. La regulación definitiva de la profesión no se produciría hasta el siglo XIX, coincidiendo con el desarrollo independiente de la Topografía. Por una real cédula del 21 de abril de 1828 se restablecía la situación anterior a 1808, ratificando la necesidad de título para el ejercicio de la misma y la prohibición de darlo a

37 ORELlanA (s.f.), pp. 574-576.

38 Esteban, M. y Jalón, M. (1990), «Una Academia de Matemáticas en el Valladolid ilustrado», Ciencia, técnica y estado en la España ilustrada, pp. 303-319; p. 312.

39 Laborda (1989), apéndice documental. 
ciudades y tribunales ${ }^{40}$. Años más tarde, dos reales decretos de 17 de febrero de 1852 y 4 de diciembre de 1871 fijarían definitivamente las condiciones del examen y las atribuciones del agrimensor aprobado ${ }^{41}$. En un decreto anterior de fecha 31 de julio de $1821^{42}$ se especificaba que:

a) La solicitud de examen debía presentarse ante la Diputación Provincial correspondiente acompañada de la partida de bautismo del aspirante y de certificaciones de buena conducta y de las prácticas realizadas por el mismo.

b) El examen tenía que verificarse ante el Ministerio de Gracia y Justicia, que era el encargado de la expedición del título y de su remisión a la Cancillería Real.

c) El título debía registrarse en el Archivo del Sello y la Contaduría de Valores y remitido a la Diputación Provincial de origen, donde el agrimensor debía realizar el juramento habitual.

d) El coste total de este proceso ascendía a cerca de 500 reales de vellón.

e) Las dietas que percibían los agrimensores a partir de ese momento variaban de una audiencia a otra, siendo mayores en el caso de la de Madrid. Los trabajos particulares quedaban al acuerdo de las partes, pero se fijaba como referencia lo acostumbrado en la Corte: 60 reales de dieta, además del coste del viaje y la manutención.

\section{CONCLUSIÓN}

La creación de la Real Academia de Bellas Artes de San Carlos no resolvió, por si sola, los problemas que se venían denunciando desde comienzos de siglo referidos al ejercicio de la agrimensura en la ciudad de Valencia. No obstante, sería un error considerar que la situación no había experimentado modificaciones sustanciales. En la medida que existía una posibilidad de controlar la titulación de los nuevos agrimensores, la regulación del empleo sólo era cuestión de tiempo: la consolidación de la nueva corporación profesional llevaría, tarde o temprano, al acuerdo sobre unas demandas comunes y a la exigencia de mayor protección.

La guerra de la Independencia paralizó un proceso que sólo pudo reemprenderse a partir de 1828. Que se iniciara en la ciudad de Valencia se explica por la tradición que en ella tenía el oficio de experto en agricultura, la presencia de un ambiente de renovación científica propicio desde finales del siglo XVII, la centralización política

\footnotetext{
40 Colección de reales órdenes comunicadas a la Real Academia de San Carlos desde el año 1770 hasta el de 1828 (1828), Valencia, pp. 123-124.

41 CAPEL (1982), p. 314.

42 VERDEJO, F. (1841), Guía práctica de agrimensores y labradores, ó tratado completo de Agrimensura y Aforage, Madrid, pp. 14-16.
} 
que siguió a los decretos de Nueva Planta y las necesidades técnicas a las que tuvo que hacer frente el municipio ante el aumento demográfico, la lucha contra las condiciones físicas del término y la proliferación de pleitos por cuestiones territoriales.

La renovación consiguiente acabó afectando a un colectivo anclado en comportamientos que imitaban a los del sistema gremial: el de los expertos en agricultura. $\mathrm{Su}$ resistencia al cambio fue menor que la ofrecida por otros oficios, sobre todo porque no constituía un gremio y nunca se planteó su desaparición. Con agrimensores o sin ellos, el recurso a labradores conocedores del terreno continuaría siendo la norma. A finales de siglo, las diferencias entre unos y otros distaban de ser reconocidas. La confusión se explica por los lazos de vecindad, amistad e, inclusive, familiares que existían entre expertos y agrimensores; por el prestigio alcanzado en su trabajo por algunos expertos; por la actuación de los agrimensores titulados, que tendió a reproducir los hábitos de los expertos; por la falta de interés de los propios municipios (la contratación de titulados era más cara); y, en fin, por la actuación timorata de la propia academia a la hora de defender los intereses profesionales de sus titulados.

La Academia de San Carlos acabó convirtiéndose en un remedo de las propuestas que desde comienzos del siglo pedían la creación de centros para la formación de los peritos. Obligada por la ciudad a incluir la regulación de la agrimensura entre sus competencias, nunca supo cómo actuar para conseguirlo. Dedicada casi por entero a preservar su autonomía respecto de la madrileña de San Fernando y a desmantelar el sistema gremial en el campo de las bellas artes, siempre contempló esta obligación como algo carente de interés. Se limitó a establecer lo que el consistorio le pedía: una prueba de conocimientos mínimos, como trámite formal para el desempeño de la profesión. Resultó una medida insuficiente porque sus estatutos reconocían los títulos precedentes; su vinculación con la ciudad de Valencia hizo que su actuación se viese, al menos al principio, como una continuidad en el ejercicio de las competencias municipales; nunca se preocupó de dar publicidad a la norma que establecía la obligatoriedad de pasar un examen para el ejercicio de la profesión; el contenido de éste no garantizaba la cualificación de los aprobados; y en ningún momento contempló la posibilidad de ampliar sus actividades docentes a los agrimensores.

Los factores anteriores explican las dificultades que los aprobados encontraban al intentar ejercer sus derechos. Confundidos con los expertos, poco valorados por colectivos mejor preparados como los de arquitectos e ingenieros militares, deudores de los medidores formados al margen de la academia y olvidados por ésta una vez que superaban el examen preceptivo, su situación no era muy distinta en 1808 de la de mediados de siglo. Los agrimensores se encontraron, así, ante una realidad contradictoria: mientras las insuficiencias del trabajo de los expertos habían forzado un proceso que les había permitido consolidar la presencia del oficio en las instituciones, las posibilidades de contratación decrecían a medida que aumentaba el número de aprobados y la competencia ilegal de los mismos expertos. 
LA REAL ACADEMIA DE BELLAS ARTES DE SAN CARLOS Y EL EJERCICIO DE LA AGRIMENSURA

\section{ANEXO: Agrimensores titulados por la Real Academia de Bellas Artes de San Carlos de Valencia (1768-1808)}

A) Valencianos:

\begin{tabular}{|c|c|c|}
\hline NOMBRE & LOCALIDAD & APROBACIÓN \\
\hline Aguilar, Pascual & Sot de Ferrer & 18/VIII/1803 \\
\hline Aleixandre, Gregorio & Sagunt & 18/XII/1802 \\
\hline Almela, Pedro & Vila-real & 15/IV/1806 \\
\hline Almiñana, Vicente & Cofrentes & $8 / \mathrm{I} / 1801$ \\
\hline Álvarez, Juan Bautista & Valencia & $10 / \mathrm{X} / 1779$ \\
\hline Amengual, Pedro & Orihuela & 22/XII/1807 \\
\hline Andrés, Bautista & Soneja & 10/III/1801 \\
\hline Andrés, Francisco & Llíria & 16/VIII/1778 \\
\hline Andrés, Miguel & Llíria & 3/VII/1773 \\
\hline Andreu, Ramón & Alicante & $8 / \mathrm{I} / 1797$ \\
\hline Andreu, Ramón & Orihuela & 13/VI/1805 \\
\hline Aracil, Victoriano & Sant Vicent del Raspeig & 6/IV/1808 \\
\hline Arnal, Vicente & Sagunt & $31 / \mathrm{I} / 1802$ \\
\hline Asnar, Francisco & Elx & 18/VII/1792 \\
\hline Assins, Francisco & Catarroja & 3/XII/1797 \\
\hline Baldellón, José Estanislao & Alberic & 2/III/1803 \\
\hline Baller, Francisco & Castellón de la Plana & 28/VII/1800 \\
\hline Ballester, Bartolomé & Valencia & 18/II/1785 \\
\hline Ballester, Bautista & Onda & 7/VIII/1807 \\
\hline Ballester, Manuel & Castellón de la Plana & 29/VII/1781 \\
\hline Ballester, Vicente & Almassora & 12/XII/1804 \\
\hline Bañuls, José & Alicante & 9/II/1784 \\
\hline Belda, Pedro & Novelda & 28/V/1806 \\
\hline Bella, Antonio & Castelló de Xàtiva & 21/VI/1784 \\
\hline Bergadá, Miguel & Llíria & 29/I/1800 \\
\hline Bernabé, José & Elda & 5/III/1798 \\
\hline Bernabeu, Pedro & Orihuela & 15/IX/1806 \\
\hline Berruti, Juan Bautista & Alicante & $5 / \mathrm{V} / 1797$ \\
\hline Blasco, Pascual & Aspe & 13/II/1798 \\
\hline Bobea, Joaquín & Almassora & 8/XI/1805 \\
\hline Bonet, Francisco & Albalat de la Ribera & 21/IV/1803 \\
\hline Borrell, Francisco & Aielo de Malferit & 2/X/1791 \\
\hline Bru, Antonio & Massanassa & $24 / \mathrm{I} / 1803$ \\
\hline Brufal, Juan & Elx & $6 / \mathrm{VI} / 1787$ \\
\hline Calabuig, Isidro & Ontinyent & 7/I/1798 \\
\hline Calabuig, Tomás & Ontinyent & 9/VII/1799 \\
\hline Calatayud, José & Crevillent & 27/V/1791 \\
\hline Camarena, Francisco & Carcaixent & 22/VIII/1799 \\
\hline Camps, Miguel & Montcada & 30/IX/1807 \\
\hline Cañizares, Juan Bautista & Aspe & 16/XII/1805 \\
\hline Caños, Vicente & Moncofa & 23/IV/1796 \\
\hline Carbonell, José & Sueca & 4/II/1808 \\
\hline Casanova, Tomás & Valencia & 31/VII/1768 \\
\hline Casanova, Vicente & Valencia & 26/IV/1788 \\
\hline Casas, Antonio & Alginet & 14/III/1781 \\
\hline Castelló, Francisco & Sagunt & 15/II/1800 \\
\hline
\end{tabular}


ALFREDO FAUS PRIETO

Catalá, Antonio

Cerdá, Mariano

Cervera, Gaspar

Cervera, Vicente

Colechá, Bernardo

Coltell, Bartolomé

Coltell, Tomás

Comeche, Vicente

Conejos, José

Conques, Pascual

Cortés, Antonio

Crúa, Vicente

Cuenca, Francisco

Cuenca, Miguel

Chaix, José

Chornet, Antonio

Chulvi, José

Darés, José

David, Juan

Díez, Francisco

Domingo, Juan

Felici, Francisco

Fenoll, Juan

Fenollosa, Julián

Fernández, Francisco

Ferrer, Miguel

Fons, José

Font, Vicente

Fraga, Bartolomé

Gandía, Pascual

Garañena, José

García, José

García, Juan

Gari, Bautista

Gavara, Mariano

Girona, Roque

Gómez, Manuel

González, Manuel

Guijarro, Francisco

Heredia, Miguel

Herráez, Antonio

Ibars, Manuel

Iborra, Eusebio

Iglesias, Bautista

Iranzo, Tomás

Jordán, Rafael

Juan, José

La Iglesia, Pedro

Langa, Pablo

Lapuente, José

Lima, Vicente

Linares, Vicente

Lisian, Francisco Antonio

López, José

López, Vicente

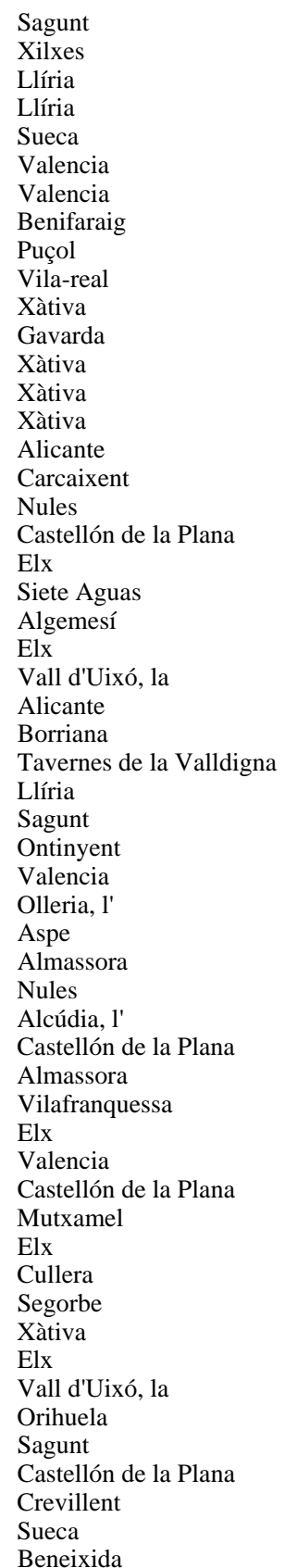

Beneixida
17/II/1798

1/II/1800

9/III/1776

8/VI/1776

4/VII/1792

4/XII/1799

13/IV/1807

$30 / \mathrm{XII} / 1800$

5/III/1799

27/IV/1805

$11 / \mathrm{X} / 1800$

4/VII/1807

9/V/1796

20/XI/1797

20/VII/1786

5/V/1797

7/I/1792

2/XII/1789

29/V/1774

25/IV/1785

29/VI/1794

$12 / \mathrm{I} / 1780$

18/VI/1790

$15 / \mathrm{V} / 1790$

14/XI/1794

13/X/1795

5/IV/1791

6/XII/1773

22/I/1804

14/VI/1800

24/XI/1805

20/I/1802

18/IX/1805

27/IX/1802

8/II/1805

$13 / \mathrm{I} / 1780$

14/XII/1791

16/IX/1775

$30 / \mathrm{I} / 1792$

13/VIII/1773

22/V/1804

2/I/1789

8/I/1806

19/X/1785

30/XI/1777

17/I/1794

24/IV/1804

8/VIII/1778

2/III/1790

30/IX/1791

24/VI/1800

7/IX/1800

14/VIII/1783

4/VII/1792

9/XXI/1807 
LA REAL ACADEMIA DE BELLAS ARTES DE SAN CARLOS Y EL EJERCICIO DE LA AGRIMENSURA

Llácer, Vicente
Llebres, Ignacio
Lledó, José
Lli, Bautista
Llop, Jaime
Llop, Juan
Llopis, José
Llopis, Manuel
Maciá, Juan
Marc, Francisco
Marhe, Miguel
Martí, Bautista
Martí, Jacinto
Martínez, Antonio
Martínez, Félix
Martínez, Francisco
Martínez, Francisco Andrés
Martínez, Lorenzo
Martínez, Miguel
Mas, Francisco
Mas, Salvador
Masía, Francisco
Matoses, Pedro Juan
Medina, Bernardo
Medrano, Antonio
Michavila, Luis
Minguet, Mauro
Miralles, Cristóbal
Miralles, Onofre
Mirambell, Ginés
Molina, Miguel
Montaner, Peregrino
Mora, Francisco
Mora, Juan
Morelló, Roque
Murcia, José
Murcia, Juan Antonio
Murcia, Miguel
Museros, Joaquín
Nacher, Pascual
Navarro, José
Navarro, Pedro
Nebot, Cristóbal
Nebot, Vicente
Olmos, Pedro Pablo
Onteniente, Diego
Ortí, Joaquín
Ortiz, Andrés
Ortiz, Francisco
Ortiz, Manuel
Oxea, Antonio
Parrell, José
Pastor, Ignacio
Pastor, Juan
Pedraza, Isidro

Asclepio-Vol. LIII-2-2001

\begin{tabular}{ll} 
Sueca & 23/XI/1786 \\
Elx & $26 / \mathrm{IV} / 1781$ \\
Sueca & $26 / \mathrm{VII} / 1781$ \\
Cullera & $26 / \mathrm{IV} / 1796$ \\
Vila-real & $23 / \mathrm{XI} / 1805$ \\
Vila-real & $27 / \mathrm{IX} / 1802$ \\
Quart de Poblet & $17 / \mathrm{III} / 1806$ \\
Sagunt & $28 / \mathrm{XI} / 1797$ \\
Elx & $12 / \mathrm{V} / 1791$ \\
Polinyà de Xúquer & $28 / \mathrm{XII} / 1778$ \\
Onda & $29 / \mathrm{IV} / 1797$ \\
Borriana & $22 / \mathrm{IV} / 1799$ \\
Alicante & $3 / \mathrm{VI} / 1795$ \\
Llíria & $29 / \mathrm{I} / 1800$ \\
Llosa de Ranes & $24 / \mathrm{I} / 1803$ \\
Novelda & $4 / \mathrm{VI} / 1806$ \\
Orihuela & $8 / \mathrm{IX} / 1806$ \\
Valencia & $13 / \mathrm{V} / 1768$ \\
Xàtiva & $23 / \mathrm{IV} / 1792$ \\
Crevillent & $22 / \mathrm{II} / 1789$ \\
Crevillent & $4 / \mathrm{VIII} / 1783$ \\
Elx & $13 / \mathrm{V} / 1779$ \\
Cullera & $10 / \mathrm{I} / 1785$ \\
Valencia & $6 / \mathrm{XII} / 1800$ \\
Alicante & $28 / \mathrm{VI} / 1794$ \\
Onda & $9 / \mathrm{III} / 1777$ \\
Valencia & $13 / \mathrm{V} / 1768$ \\
Castellón de la Plana & $10 / \mathrm{I} / 1796$ \\
Valencia & $5 / \mathrm{VII} / 1772$ \\
Monforte del Cid & $20 / \mathrm{XII} / 1781$ \\
Vila-real & $14 / \mathrm{VII} / 1790$ \\
Paterna & $14 / \mathrm{VI} / 1800$ \\
Callosa de Segura & $29 / \mathrm{VIII} / 1807$ \\
Callosa de Segura & $18 / \mathrm{IV} / 1787$ \\
Segorbe & $21 / \mathrm{II} / 1803$ \\
Orihuela & $10 / \mathrm{VI} / 1796$ \\
Orihuela & $20 / \mathrm{X} / 1802$ \\
Orihuela & $10 / \mathrm{VII} / 1796$ \\
Castellón de la Plana & $14 / \mathrm{V} / 1799$ \\
Vila-real & $23 / \mathrm{XI} / 1805$ \\
Alaquàs & $22 / \mathrm{III} / 1793$ \\
Nules & $29 / \mathrm{VIII} / 1805$ \\
Vila-real & $11 / \mathrm{I} / 1791$ \\
Betxí & $10 / \mathrm{VI} / 1796$ \\
Valencia & $5 / \mathrm{XI} / 1778$ \\
Alicante & $6 / \mathrm{VIII} / 1802$ \\
Sueca & $29 / \mathrm{III} / 1780$ \\
Callosa de Segura & $11 / / \mathrm{III} / 1791$ \\
Buñol & $20 / \mathrm{XII} / 1781$ \\
Callosa de Segura & $11 / \mathrm{III} / 1791$ \\
Orihuela & $11 / \mathrm{VII} / 1803$ \\
Sueca & $5 / \mathrm{XII} / 1794$ \\
Cullera & $10 / \mathrm{I} / 1806$ \\
Alicante & $3 / \mathrm{VIII} / 1800$ \\
Mutxamel & $23 / \mathrm{VII} / 1794$ \\
\hline & \\
&
\end{tabular}


ALFREDO FAUS PRIETO

Peiró, Vicente Perales, Vicente

Pérez, Vicente

Pérez, Vicente

Pina, Diego

Piñón, Matías

Plá, Felipe

Pujol, Ramón

Querol, Francisco

Ramos, Joaquín

Ramos, Pedro

Redal, Antonio

Rico, José

Rocafort, Jaime

Ros, José

Rosell, José

Ruiz, Joaquín

Ruiz, Mateo

Salbar, Antonio

Sanchis, Antonio

Sanchiz, Pascual

Sancho, José

Sebastiá, Pascual

Segarra, Nicolás

Segura, Vicente

Sellés, Manuel

Soler, Mariano

Soriano, Francisco

Teixedo, Miguel

Terol, José

Terres, José

Tormo, José

Torregrosa, Vicente

Torres, Ahino

Torres, Pedro

Valls, Manuel

Vicent, Miguel

Vidal, José

Villa, José

Villato, Manuel Tomás

Villeta, Giner

Vives, Francisco

Vives, Isidro

Vives, José

Ximeno, Blas

Ximeno, José
Soler, Luis

\begin{tabular}{|c|c|}
\hline Alaquàs & 22/III/1793 \\
\hline Guadassuar & 18/IV/1780 \\
\hline Alzira & $31 / \mathrm{III} / 1800$ \\
\hline Vila-real & $8 / \mathrm{XI} / 1805$ \\
\hline Callosa de Segura & $18 / \mathrm{X} / 1800$ \\
\hline Onda & 29/IV/1797 \\
\hline Artana & 23/III/1795 \\
\hline Alicante & 5/V/1797 \\
\hline Castellón de la Plana & 9/VII/1788 \\
\hline Borriana & $15 / \mathrm{X} / 1795$ \\
\hline Crevillent & 17/XI/1791 \\
\hline Alzira & $5 / \mathrm{IV} / 1800$ \\
\hline Monòver & $8 / I I I / 1785$ \\
\hline Castellón de la Plana & $5 / \mathrm{XI} / 1790$ \\
\hline Sagunt & 3/VII/1799 \\
\hline Montcada & 26/IX/1791 \\
\hline Elx & $21 / \mathrm{XI} / 1783$ \\
\hline Llíria & 1/VI/1778 \\
\hline Museros & $8 / I X / 1800$ \\
\hline Carcaixent & 8/XII/1807 \\
\hline Carcaixent & 20/I/1794 \\
\hline Vila-real & $14 / \mathrm{I} / 1792$ \\
\hline Sagunt & 27/III/1798 \\
\hline Castellón de la Plana & $13 / \mathrm{V} / 1789$ \\
\hline Valencia & 19/II/1793 \\
\hline Bétera & $5 / \mathrm{II} / 1798$ \\
\hline Algemesí & $9 / \mathrm{V} / 1786$ \\
\hline Xàtiva & 9/I/1808 \\
\hline Vila-real & 27/VII/1790 \\
\hline Borriana & $10 / \mathrm{X} / 1795$ \\
\hline Alicante & 4/IV/1799 \\
\hline Benejúzar & 4/IV/1794 \\
\hline Ontinyent & 9/III/1793 \\
\hline Sant Vicent del Raspeig & $28 / \mathrm{II} / 1805$ \\
\hline Corbera & 19/VIII/1807 \\
\hline Valencia & 23/II/1772 \\
\hline Ontinyent & 9/IV/1805 \\
\hline Vila-real & $11 / \mathrm{I} / 1791$ \\
\hline Vila-real & $11 / \mathrm{I} / 1791$ \\
\hline Castellón de la Plana & 28/V/1802 \\
\hline Orihuela & 1/IX/1792 \\
\hline Alicante & $5 / \mathrm{V} / 1797$ \\
\hline Carcaixent & 10/VI/1794 \\
\hline Carcaixent & 3/III/1808 \\
\hline Onda & 15/VII/1807 \\
\hline Salinas & 2/IV/1797 \\
\hline Betxí & 16/VI/1797 \\
\hline
\end{tabular}

B) Foráneos al Reino de Valencia:

\begin{tabular}{lll}
\hline NOMBRE & LOCALIDAD (PROVINCIA) & APROBACIÓN \\
\hline Agenjo, Pedro & Rubielos de Mora (4) & $6 /$ VII/1795 \\
Alarcón, Blas & Minaya (1) & 24/V/1797 \\
140 & & Asclepio-Vol. LIII-2-2001
\end{tabular}


LA REAL ACADEMIA DE BELLAS ARTES DE SAN CARLOS Y EL EJERCICIO DE LA AGRIMENSURA

Alarcón, Juan de

Albertos, Diego

Andrés, Juan

Andreu, Ramón

Bañón, José

Berdejo, Juan

Berdexo, Miguel

Blanco, Miguel

Blasco, Martín

Cambronero, Fernando

Cánovas, Pedro de

Capel, Bernardo

Caro, Alonso

Carpena, Juan

Carra, José

Cebrián, Cristóbal

Córdoba, Blas Ignacio

Cosías, Juan Pío

Cubas, Martín de

Cuesta, Alonso

Cuesta, Francisco

Cuesta, Pedro de la

Díaz, Aquilino Antonio

Díaz, Pedro

Fernández, José

Fernández, Juan

Fernández, Julián

Fernández, Ramón

Flores, Manuel de

García, Alonso José

García, Andrés

García, Antonio

García, Antonio

García, Fernando

García, José

García, José

García, José Joaquín

García, Matías

García, Pedro

García, Pedro

García, Pedro

García, Tomás

García, Tomás Antonio

Garrido, Melchor

Garrido, Tomás

Gómez, Andrés

González, Miguel

Guinao, Antonio

Hernández, Ginés

Hernández, Pedro

Lax, José

Leal, Juan

López, Antonio

López, Eusebio

López, Juan
Minaya

Abengibre (1)

Yecla (3)

Almansa (1)

Caudete (1)

Ledaña (2)

Jorquera (1)

Almansa

Jorquera

San Clemente (2)

Alhama de Murcia (3)

Líjar (8)

Villanueva de La Jara (2)

Yecla

San Clemente

Jorquera

Villalpardo (2)

Honrubia (2)

Ledaña

Motilleja (1)

Albacete (1)

Jorquera

Barrax (1)

Caudete

La Roda (1)

Villanueva de La Jara

La Roda

Castropol (6)

Villagordo del Júcar (2)

Tobarra (1)

Ledaña

Madrigueras (1)

La Roda

Murcia (3)

Madrigueras

Murcia

La Roda

Jorquera

Murcia

Murcia

Murcia

Iniesta (1)

Villanueva de La Jara

Madrigueras

Motilleja (1)

Jorquera

Alcalá del Júcar (1)

Cieza (3)

Murcia

Cartagena (3)

Murcia

Madrigueras

Iniesta

Chinchilla de Monte Aragón

Iniesta
22/I/1794

20/VI/1792

12/VIII/1799

$8 / \mathrm{I} / 1797$

9/V/1806

20/VII/1792

2/VI/1792

$8 / \mathrm{I} / 1797$

13/III/1792

26/V/1794

26/VIII/1807

4/IV/1794

22/II/1800

17/VI/1799

30/I/1806

6/VII/1793

18/VI/1792

17/VI/1805

30/V/1792

4/II/1793

6/VI/1792

26/XI/1791

26/V/1807

4/V/1791

27/VI/1792

28/I/1800

27/VI/1792

21/II/1801

$16 / \mathrm{VI} / 1794$

30/V/1795

2/IV/1793

29/V/1792

27/VI/1802

9/I/1801

1/X/1791

30/IV/1805

24/VIII/1797

20/V/1791

$31 / \mathrm{I} / 1795$

30/V/1795

9/III/1807

26/VI/1798

21/I/1801

5/VII/1792

4/II/1793

18/VI/1799

3/VII/1793

10/VII/1795

8/VI/1805

25/VIII/1807

12/IX/1807

23/VII/1793

17/VIII/1792

15/IV/1806

28/V/1802 
ALFREDO FAUS PRIETO

\begin{tabular}{l} 
López, Juan Fausto \\
López, Julián \\
López, Miguel \\
Martín, Cristóbal \\
Martín, Isidro \\
Martínez, Antonio \\
Martínez, Domingo \\
Martínez, Pedro \\
Mateo, Antonio \\
Mateo, Rafael Felipe \\
Morata, Cayetano \\
Moreno, Angel \\
Moreno, Lorenzo \\
Muñoz, Sebastián \\
Navarro, Julián \\
Navarro, Miguel \\
Nieto, Antonio \\
Núñez, Vicente \\
Ortega, Juan \\
Pardo, Julián \\
Pardo, Matías \\
Parra, José \\
Parreño, Lorenzo \\
Pedrero, Salvador \\
Pérez, José \\
Pérez, Marcos \\
Pérez, Pedro \\
Pérez, Pedro \\
Picazo, Juan Miguel \\
Polo, José \\
Ponce, Fernando \\
Ponce, Pedro \\
Poveda, Antonio \\
Ramírez, José \\
Ravadán, Cristóbal \\
Ródenas, Alfonso \\
Rombau, Pascual \\
Ruiz, José \\
Sáez, Domingo \\
Sánchez, Simón \\
Sanchis, Antonio \\
Sevilla, Miguel \\
Tobarra, Francisco \\
Tórtola, José \\
Torre, Nicolás \\
Torres, José \\
Valverde, Pedro \\
Villora, Juan \\
Ximénez, Ginés \\
Zamora, José \\
Zerero, Pedro \\
\hline
\end{tabular}

$\begin{array}{ll}\text { San Clemente } & \text { 8/I/1800 } \\ \text { San Clemente } & 24 / \mathrm{VI} / 1792 \\ \text { Iniesta } & 14 / \mathrm{III} / 1799 \\ \text { Lillo (5) } & 15 / \mathrm{VII} / 1797 \\ \text { Madridejos (5) } & 2 / \mathrm{X} / 1795 \\ \text { Cartagena } & 9 / \mathrm{III} / 1801 \\ \text { Cartagena } & 8 / \mathrm{XI} / 1807 \\ \text { Villagordo del Júcar } & 16 / \mathrm{VI} / 1794 \\ \text { Bonete (1) } & 15 / \mathrm{VI} / 1804 \\ \text { Cuenca (2) } & 3 / \mathrm{XII} / 1804 \\ \text { Murcia } & 2 / \mathrm{VII} / 1798 \\ \text { Caravaca de la Cruz (3) } & 26 / \mathrm{III} / 1797 \\ \text { San Clemente } & 21 / \mathrm{I} / 1801 \\ \text { La Roda } & 27 / \mathrm{VI} / 1792 \\ \text { Jorquera } & 26 / \mathrm{XI} / 1791 \\ \text { Barrax } & 10 / \mathrm{VIII} / 1807 \\ \text { Cartagena } & 17 / \mathrm{I} / 1803 \\ \text { Población de Campos (7) } & 20 / \mathrm{XII} / 1802 \\ \text { Yecla } & 6 / \mathrm{XII} / 1789 \\ \text { Villanueva de La Jara } & 5 / \mathrm{VIII} / 1800 \\ \text { Jorquera } & 2 / \mathrm{VI} / 1792 \\ \text { Caudete } & 9 / \mathrm{V} / 1805 \\ \text { La Roda } & 27 / \mathrm{VI} / 1792 \\ \text { Fuente Álamo (3) } & 5 / \mathrm{VII} / 1805 \\ \text { San Clemente } & 8 / \mathrm{I} / 1800 \\ \text { Alcalá de Júcar } & 18 / \mathrm{VI} / 1803 \\ \text { Iniesta } & 21 / \mathrm{IX} / 1793 \\ \text { Antonio Yecla } & 17 / \mathrm{VII} / 1789 \\ \text { Villagordo del Júcar } & 6 / \mathrm{VII} / 1793 \\ \text { Cartagena } & 17 / \mathrm{IV} / 1805 \\ \text { Madrigueras } & 21 / \mathrm{V} / 1792 \\ \text { Ledaña } & 26 / \mathrm{XI} / 1791 \\ \text { Motilla del Palancar (2) } & 14 / \mathrm{VI} / 1797 \\ \text { Beniel (3) } & 18 / \mathrm{I} / 1806 \\ \text { Casasimarro (2) } & 27 / \mathrm{VI} / 1793 \\ \text { Chinchilla de Monte Aragón } & 22 / \mathrm{IV} / 1800 \\ \text { Abengibre } & 12 / \mathrm{XI} / 1789 \\ \text { Jorquera } & 3 / \mathrm{IV} / 1791 \\ \text { Jorquera } & 10 / \mathrm{VIII/1792} \\ \text { La Roda } & 27 / \mathrm{VI} / 1802 \\ \text { Murcia } & 21 / \mathrm{VI} / 1805 \\ \text { Tobarra } & 30 / \mathrm{V} / 1795 \\ \text { La Gineta (1) } & 18 / \mathrm{II} / 1793 \\ \text { Campillo de Altobuey (2) } & 14 / \mathrm{III} / 1795 \\ \text { Murcia } & 17 / \mathrm{X} / 1795 \\ \text { Alcalá de Júcar } & 30 / \mathrm{VIII} / 1803 \\ \text { Ledaña } & 10 / \mathrm{VI} / 1800 \\ \text { Motilla del Palancar } & 12 / \mathrm{IX} / 1792 \\ \text { Tarazona de la Mancha (1) } & 14 / \mathrm{I} / 1799 \\ \text { Rubielos de Mora } & 23 / \mathrm{VIII/1803} \\ \text { Yecla } & 6 / \mathrm{IV} / 1808 \\ & \\ & \\ & \end{array}$

Provincias actuales: (1) Albacete; (2) Cuenca; (3) Murcia; (4) Teruel; (5) Toledo; (6) Asturias; (7) Palencia y (8) Almería. 